\section{References}

1. Brix-Christensen V. The systemic inflammatory response after cardiac surgery with cardiopulmonary bypass in children. Acta Anaesthesiol Scand. 2001;45:671-9.

2. Lien E, Means TK, Heine H, Yoshimura A, Kusumoto S, Fukase K, et al. Toll-like receptor 4 imparts ligand-specific recognition of bacterial lipopolysaccharide. J Clin Invest. 2000;105:497-504.

3. Dybdahl B, Wahba A, Lien E, Flo TH, Waage A, Qureshi N, et al.
Inflammatory response after open heart surgery: release of heat-shock protein 70 and signaling through toll-like receptor-4. Circulation. 2002; 105:685-90.

4. Riordan SM, Skinner N, Nagree A, McCallum H, McIver CJ, Kurtovic $\mathrm{J}$, et al. Peripheral blood mononuclear cell expression of toll-like receptors and relation to cytokine levels in cirrhosis. Hepatology. 2003; 37:1154-64

5. Zhang G, Ghosh S. Toll-like receptor-mediated NF-kappaB activation: a phylogenetically conserved paradigm in innate immunity. $J$ Clin Invest. 2001;107:13-9.

\title{
Modified minimally invasive coronary artery bypass after radical treatment for left breast cancer
}

Toshiya Ohtsuka, MD, Mikio Ninomiya, MD, Takahiro Nonaka, MD, and Taisei Maemura, MD, Tokyo, Japan

$\mathrm{M}$ inimally invasive coronary artery bypass (MICAB) customarily means off-pump coronary artery bypass with a limited approach and is generally performed through a left anterior small thoracotomy by using the internal thoracic artery (ITA). ${ }^{1}$ This communication describes a modified MICAB technique with a video-assisted left subcostal approach, in which the left anterior descending artery (LAD) was revascularized with a saphenous vein (SV) graft by using an inflow from the right axillary artery. This procedure was applied to a female octogenarian who had undergone a radical left mastectomy and adjunctive radiation therapy for advanced left breast cancer.

\section{Methods}

An 81-year-old woman presented with unstable angina caused by an LAD lesion for which surgical intervention was indicated. Twenty years before, the patient had undergone a left mastectomy and extensive left axillary lymph node dissection because of advanced left breast carcinoma. The soft tissue component (adipose tissue and muscle) over the sternum and the left anterior bony structures had been completely removed, and the resulting skin defect over the midsternum and the left breast had been repaired by means of autograft implantation (Figure 1). Thereafter, adjunctive radiation therapy had been performed over both ITAs and the dissected left axillary area. Although there had been no cancer recurrence over the following 2 decades, ulceration had occurred

From the Department of Cardiovascular Surgery, Tokyo Metropolitan Fuchu General Hospital, Tokyo, Japan.

Received for publication Oct 15, 2003; revisions requested Nov 5, 2003; accepted for publication Nov 10, 2003.

Address for reprints: Toshiya Ohtsuka, MD, 2-9-2 Musashidai, Fuchu-shi, Tokyo 183-0042, Japan (E-mail: ootsuka-cvs@fuchu-hp.fuchu.tokyo.jp).

J Thorac Cardiovasc Surg 2004;127:1525-7

$0022-5223 / \$ 30.00$

Copyright $\odot 2004$ by The American Association for Thoracic Surgery

doi:10.1016/j.jtcvs.2003.11.053

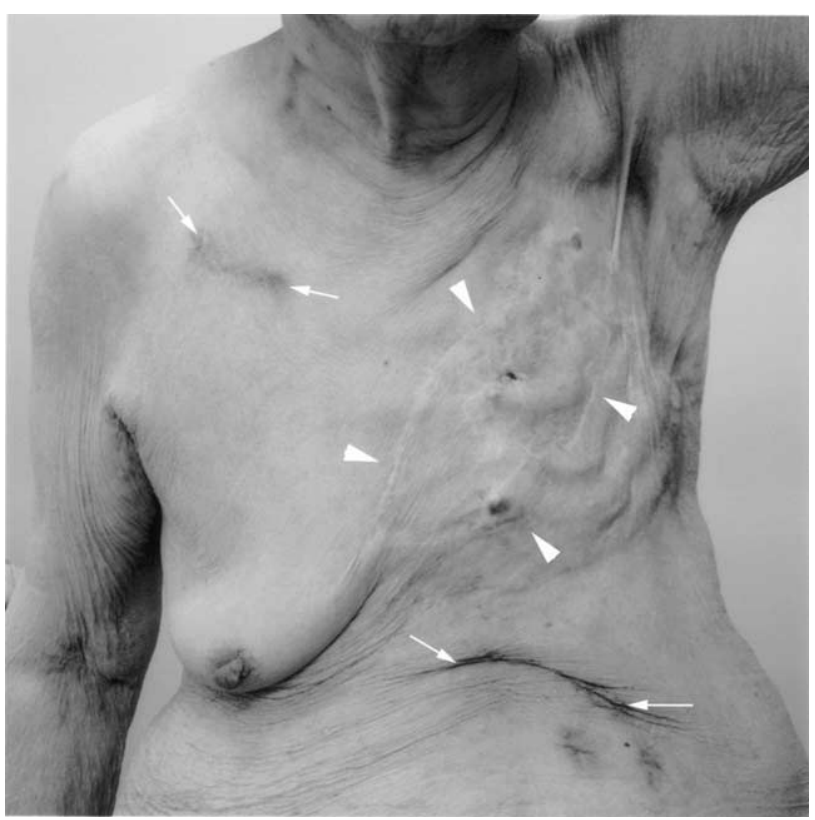

Figure 1. Photograph of patient's chest showing right subclavicular $(4 \mathrm{~cm})$ and left subcostal $(6 \mathrm{~cm})$ skin incisions (arrows) and auto-skin graft over sternum and left breast (arrowheads).

repeatedly on the ischemic skin over the thin chest wall, and therefore the left anterior small thoracotomy and sternotomy approaches were inapplicable. Furthermore, angiography showed that both irradiated ITAs were very small and that the left axillary artery, which lay in the extensively dissected and irradiated region, was inappropriate as an inflow for the bypass graft.

The patient was placed in the supine position, and general anesthesia was obtained through a single-lumen endotracheal tube. A 6-cm left subcostal skin incision was made parallel to the costal arch (Figure 1), and the left abdominal rectal muscle and the left anterior part of the diaphragm were divided. The pericardium was opened, and the mid-LAD was exposed, retracting the left costal 


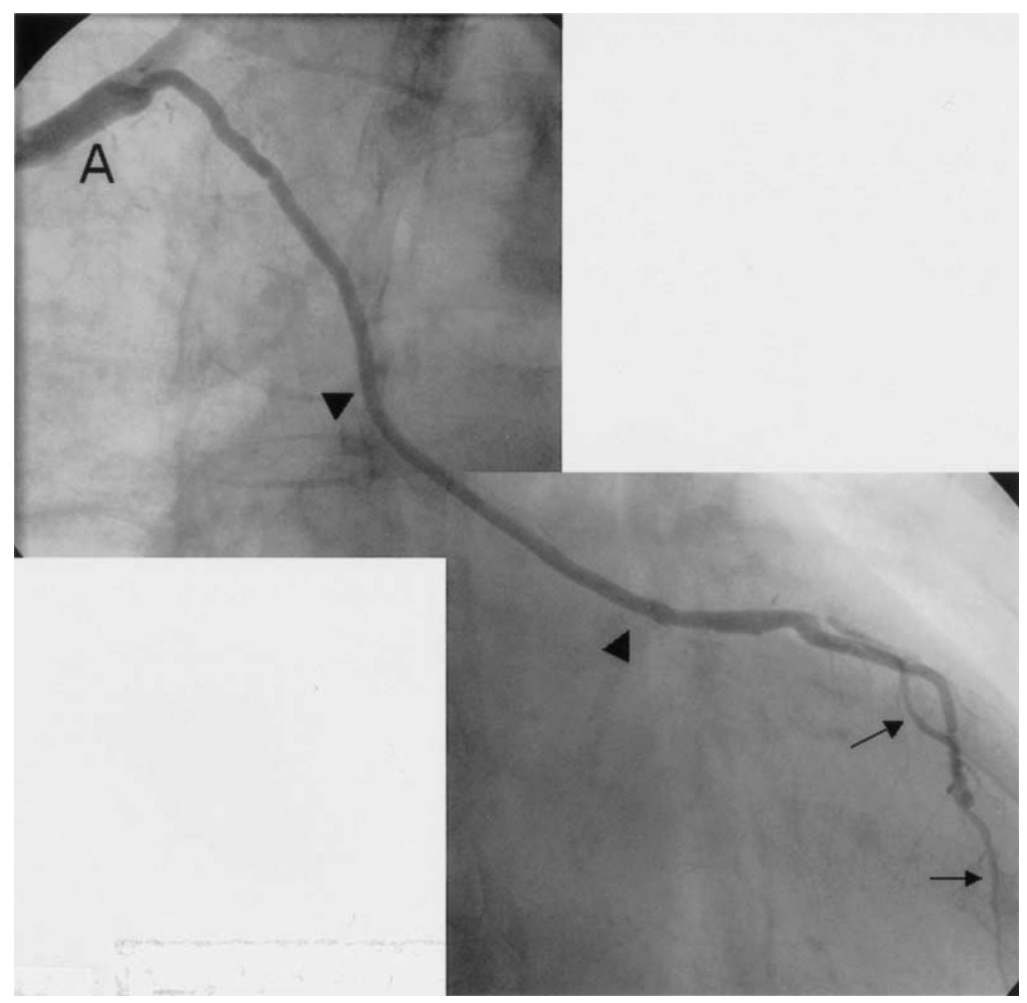

Figure 2. Postoperative angiography of SV graft (arrowheads) from right axillary artery (A) to LAD (arrows).

arch anteriorly. Palpation demonstrated that the small right gastroepiploic artery was inappropriate as a bypass graft, and therefore the SV was harvested and anastomosed to the right axillary artery through a $4-\mathrm{cm}$ subclavicular skin incision (Figure 1). The SV graft was advanced to the heart with videoscopic assistance by using a $10-\mathrm{mm}, 30^{\circ}$ rigid scope; the graft penetrated the first intercostal space, passed the right pleural cavity, and finally crossed the retrosternal space to be anastomosed to the mid-LAD. The SV-LAD anastomosis was performed on the beating heart with a stabilizer fixed to the operating table. The subcostal wound was closed, repairing the divided muscles.

\section{Results}

The operating time was 2 hours and 50 minutes, and there was no procedure-related morbidity. Angiography performed on the seventh postoperative day confirmed the patency of the SV graft (Figure 2).

\section{Discussion}

A modified MICAB through the extrathoracic entry (ie, a transabdominal approach) has been reported to provide satisfactory clinical results in patients with multivessel disease. ${ }^{2}$ Subramanian and Patel $^{2}$ suggested that a sufficient direct view of the heart could be obtained through the bottom of the thorax if the abdominal rectal muscle was divided, and traction of the costal arch was accordingly released. The present left subcostal approach for establishing a single bypass to the LAD is, in fact, a modified and limited version of their approach. Videoscopy enhanced the limited view through this abdominal minientry and was used for graft control; the SV graft from the apical intrapleural cavity through the retrosternal space was visualized in its entirety, and its pathway was verified on the video monitor.

Axillocoronary artery bypass through the minimally invasive approach has been reported to be an alternative technique to the standard ITA-MICAB in a limited number of patients, such as redo cases. ${ }^{3,4}$ In comparison with the standard aortocoronary bypass, a longer graft is needed, and the long-term graft durability is unknown. Meticulous follow-up is therefore important. In these patients the patent SV graft can be detected easily and repeatedly in the infraclavicular area by using transcutaneous echocolor Doppler scanning. ${ }^{5}$ Although the present patient has been free of angina for 6 months after the MICAB, the patency of the graft has been checked every 3 months with Doppler scanning.

In summary, a modified MICAB to the LAD involving an SV graft with right axillary arterial inflow and a video-assisted left subcostal approach was successfully accomplished in a patient with previous radical treatment for left breast cancer. Although the present method is strictly limited to only specific patients, it can be a viable alternative to the classical MICAB procedure.

\section{References}

1. Stanbridge RD, Symons GV, Banwell PE. Minimal-access surgery for coronary artery revascularisation. Lancet. 1995;346:837. 
2. Subramanian VA, Patel NU. Transabdominal minimally invasive direct coronary artery bypass grafting (MIDCAB). Eur J Cardiothorac Surg. 2000;17:485-7.

3. Coulson AS, Glasgow EF, Bonatti J. Minimally invasive subclavian/ axillary artery to coronary artery bypass (SAXCAB): review and classification. Heart Surg Forum. 2001;4:13-25.
4. Yaryura R, Vardhan R, Springer AJ, Cooley DA. A 66-year-old man with severe angina and previous coronary artery bypass. Lancet. 1997; 349:396.

5. Ohtsuka T, Suematsu Y, Kubota H, Takamoto S, Makuuchi M. Salvage of right gastroepiploic artery graft before pancreatoduodenectomy. J Thorac Cardiovasc Surg. 2001;121:1013-4.

\title{
Orthotopic mitral valve replacement with autologous pulmonary valve in a porcine model
}

\author{
Khanh Nguyen, MD, ${ }^{a}$ Justus T. Strauch, MD, ${ }^{a}$ Shubhika Srivastava, MD, ${ }^{\mathrm{b}}$ Alexander Lauten, MS, ${ }^{\text {a }}$ \\ Peter Haldenwang, MS, ${ }^{a}$ Ning Zhang, MD, ${ }^{a}$ Susan Vlahakis, CCP, ${ }^{a}$ and David H. Adams, MD, ${ }^{a}$ New York, NY
}

$\mathrm{M}$ itral valve replacement in children continues to be a challenge because of the unavailability of an ideal prosthesis. Although most patients can have a successful palliation with repair, some need valve replacement.

In the 1960s, Willman and colleagues ${ }^{1}$ made early attempts to place a semilunar valve in the orthotopic mitral position in dogs. Subsequent work involved implantation of a semilunar valve homograft or autograft in a supra-annular location in a special configuration called a top hat. $^{2}$ However, the limitation of growth inherent in this approach makes it less attractive in the pediatric population.

We have begun to investigate the possibility of implanting the pulmonary valve orthotopically in the mitral position (Figures 1 and 2). This approach retains the freedom from anticoagulation and the durability that make the top hat operation attractive but also permits growth, because there is no physical constraint from the top hat supporting tube. This report presents preliminary data in a short-term study in a porcine model on the feasibility of orthotopic mitral valve replacement with an autologous pulmonary valve.

\section{Materials and Methods}

All animals received humane care in compliance with the guidelines of "Principles of Laboratory Animal Care," formulated by the

From the Departments of Cardiothoracic Surgery ${ }^{\mathrm{a}}$ and Pediatrics, ${ }^{\mathrm{b}}$ Mount Sinai Medical Center, New York, NY.

Received for publication July 11, 2003; accepted for publication Nov 17, 2003.

Address for reprints: Khanh Nguyen, MD, Pediatric Cardiac Surgery, Department of Cardiothoracic Surgery, Mount Sinai Medical Center, Box 1028, 1190 Fifth Ave, New York, NY 10029 (E-mail: Khanh.Nguyen@mountsinai.org).

J Thorac Cardiovasc Surg 2004;127:1527-9

$0022-5223 / \$ 30.00$

Copyright $(9) 2004$ by The American Association for Thoracic Surgery

doi:10.1016/j.jtcvs.2003.11.055
National Society for Medical Research, and "Guide for the Care and Use of Laboratory Animals" (http://www.nap.edu/catalog/ $5140 . \mathrm{html})$. The protocol for this experiment was approved by our institutional animal care and use committee.

Eight juvenile pigs, weighing from 25 to $35 \mathrm{~kg}$, were studied. After intramuscular treatment with ketamine $(15 \mathrm{mg} / \mathrm{kg})$ and atropine $(0.03 \mathrm{mg} / \mathrm{kg})$, the animals were anesthetized by intravenous injection of sodium thiopental $(20 \mathrm{mg} / \mathrm{kg})$ and underwent endotracheal intubation. The subjects were ventilated mechanically with an inspired oxygen fraction of 50\%, and isoflurane at $1 \%$ to $2 \%$ was used to maintain anesthesia. Paralysis was achieved with intravenous pancuronium $(0.1 \mathrm{mg} / \mathrm{kg})$. An arterial line was placed in the right brachial artery for pressure monitoring and blood sampling $\left(\mathrm{pH}, \mathrm{Po}_{2}, \mathrm{PCO}_{2}\right.$, oxygen saturation, base excess, hematocrit, hemoglobin, glucose, and lactate, Ciba Corning 865 Blood Gas Analyzer; Chiron Diagnostic, Norwood, Mass). A left atrial line was inserted for monitoring of left atrial pressure after separation from cardiopulmonary bypass (CPB). The subjects were given inotropic support (including dobutamine at 10 $\mathrm{mg} /[\mathrm{kg} \cdot \mathrm{min}]$ and titrated with epinephrine at $100-200 \mathrm{ng} /[\mathrm{kg}$. min]) to maintain a normal mean systemic pressure of 40 to 50 $\mathrm{mm} \mathrm{Hg}$.

Surgical technique. The heart was exposed by a left thoracotomy through the 5th intercostal space. The subject was placed on $\mathrm{CPB}$, and hypothermia was induced. During cooling, and with the heart beating, the pulmonary artery was harvested by transecting it proximal to the bifurcation and disconnecting the infundibulum from the right ventricle. The aorta was crossclamped, and blood cardioplegia was given though the aortic root. The left atrium was opened, and the native mitral valve was left in situ. The pulmonary artery was prepared, the wall of one sinus was resected, and the resected sinus was oriented toward the left ventricular outflow tract. The pulmonary arterial end of the graft was anchored to the tip of the papillary muscles at four sites (Figure 3) with pledgeted 4-0 polypropylene sutures. A continuous running mattress anastomosis of the right ventricular end of the graft with 4-0 polypropylene suture was carried out 1 to $2 \mathrm{~mm}$ below the pulmonary valve annulus, plicating through the mitral leaflets close to the hinge area of the native mitral valve (Figure 1). A valved conduit (Shelhigh, Inc, Union, NJ) was placed in the right ventricular outflow tract, and the subject was removed from CPB. A trans- 